\title{
Features of managerial communication in network management
}

\author{
Marina Chernobay, Marina Pavlova, and Konstantin Tsapko* \\ Don State Technical University, 344000, Rostov-on-Don, Russia
}

\begin{abstract}
The issue of implementing BIM technologies in design organizations is becoming increasingly acute. The use of information technology raises complex questions about the organization of production. Management communication should be effective and effective. The purpose of this study is to identify the priority tasks in establishing effective communication when implementing BIM technologies in a project organization.Persistent attention to the most important issues of research methodology is a sure indicator of the growth of self-awareness in the science of management and management. The criteria of accuracy in philology and production management are reinterpreted. The problems of combining the objective and the subjective in the management text are discussed. There is an obvious need for initiative in the search for new, more subtle methods of penetration into the world of complex and increasingly complex phenomena of the labor management system. The increased attention of managers to the active participation of the employee in the improvement and implementation of the company's document flow, to the improvement of the ergonomics of production management, to the complex issues of the psychology of perception of the management text is indicative.
\end{abstract}

\section{Introduction}

The relevance of the research is determined by the intensification of production processes in the context of the transition to the digital economy and by increasing the weight of the factor of optimal choice of the management scheme of time and logistics flows in the implementation of investment projects, which allows to increase the competitiveness of construction products and the reliability of the enterprise [1]. Modern management systems are developing in conditions of radical acceleration and complication of internal and external relations, which determines the need to study the organizational and economic aspects of development and improve the management system of investment and construction projects. This area of development is also supported by the Government of the Russian Federation and includes a number of programs aimed at creating a digital economy and effective management of manufacturing industries. [2-3].

*Corresponding author: tsapko@list.ru 


\section{Materials and methods}

The digital economy and governance require special attention to the management text. The globalization of information and management communications involves not only the ability to create, find, but also to differentiate information. Therefore, the media literacy of a specialist is the most important priority of the production policy as a whole [4-6].

It should be understood that when an organization uses information modeling technologies for buildings and structures, its structure changes in comparison with the traditional one based on two-dimensional design. Figure 1 shows part of the structure of a design firm working in the field of BIM [7-9].

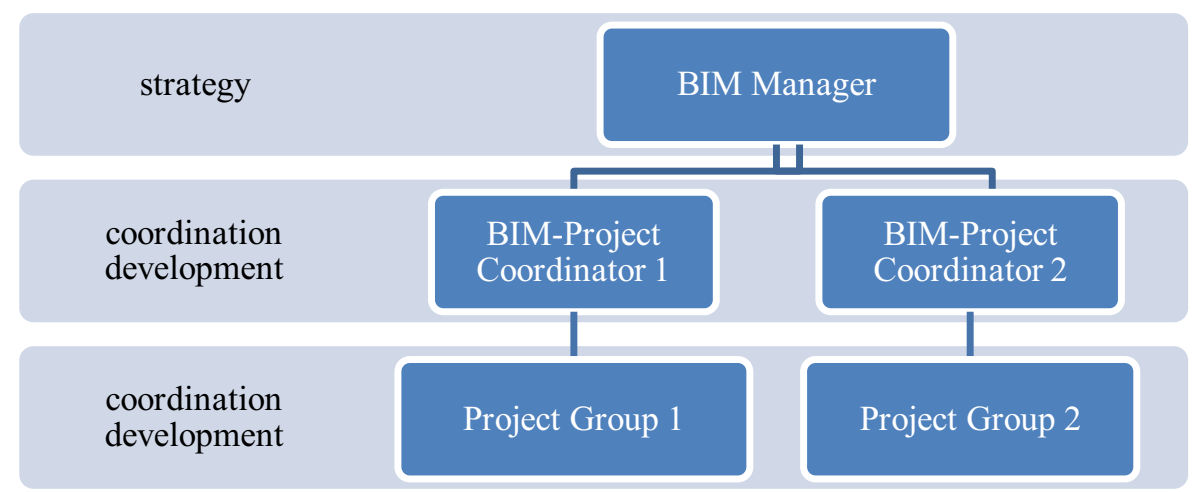

Fig. 1. Change in the organizational structure of the project firm. Developed by the author

As can be seen from Figure 1, the strategic functions of implementing and developing BIM processes are performed by the BIM manager, while the direct coordination of the project team is carried out by the BIM coordinator. Consider the main job responsibilities of a BIM manager [10].

1. Creation of a corporate standard in the field of information modeling.

2. Create a shared data environment.

3. Support for the current process.

4. Introduction of new technologies.

5. Employee training.

6. Analysis of the degree of implementation, problems.

7. Interaction with the customer's BIM manager.

The main tasks in the implementation of the technology of information modeling of buildings and structures are:

1. Organizational and structural: introduction of new positions in the enterprise, development of job descriptions, development of the implementation map.

2. Technical: purchase of the necessary software, verification of compliance and capacity of the technical equipment of the enterprise.

3. Training: staff training in new technologies.

4. Methodological: development of various standards and guidelines.

The main official responsible for the BIM implementation process is the BIM Manager. When the number of employees is up to 30 people, as a rule, it combines the functions of a manager, coordinator and master. Thus, its main tasks, which should be performed in parallel, are:

1. Development of the enterprise BIM standard-a document regulating all BIM processes in the enterprise.

2. Create a common data environment, define roles and rights of participants. 
3. Development of templates based on the corporate BIM standard.

4. Create libraries of items used in your organization's projects.

5. Team training.

6. Writing instructions. [11-13].

To perform these tasks, the BIM manager must be well versed in the stages of design, programming, modeling, be able to train, be able to find contact with people.

It follows from the above that the main functions for the implementation of BIM technologies in the project organization are performed by the BIM manager. However, factors such as the willingness of project team members to adopt new technologies and the availability of technical and instrumental resources play an equally important role in the effectiveness of implementation.

\section{Results}

Speech is a leading component of managerial information flows.. In the context of digitalization, the management of media content in the information management system, its expertise and the formation of the correct response to the negative component are crucial, since it determines the implementation of the key components of the digital economy:

- information product, which in most cases is a text;

- organizational and management tools are speech communication (network management and marketing);

- a regulatory framework that determines the feasibility, legality, technological literacy and economic feasibility of decisions made, which also represents a fixed impact on a person's speech activity in Internet communication.

Therefore, the study of the management text from the standpoint of digital literacy in the modern space remains a priority.

Constant attention to the most important issues of research methodology is a true indicator of the growth of self-awareness in the science of management and management. The criteria of accuracy in philology and production management are reinterpreted. The problems of combining the objective and the subjective in the management text are discussed. There is an obvious need for initiative in the search for new, more subtle methods of penetrating the world of complex and increasingly complex phenomena of the labor management system.

It is indicative of the increased attention of managers to the active participation of the employee in the improvement and implementation of the company's document flow, to the improvement of the ergonomics of production management, to the complex issues of the psychology of the perception of the management text.

This opens up new, not yet explored opportunities for analyzing the information component of the management text, which is usually considered (including by modern structuralists) as an internally integral, integral, closed structure that has experienced the multifaceted impact of living reality. Meanwhile, the fruitful cooperation of the humanities leads to the belief that promising ways of knowledge are associated with the study of the management text as a fundamentally open structure, open to the world, with the study of information management of production as a process.

The idea that the art of management shapes human relationships, that management is procedural in the most precise sense of the word, is becoming increasingly clear. This obliges the specialist to carefully study not only the process of creating a text, but also the process of its perception by contemporaries. In the text itself, there is a need to reveal its inner anthropological potential, its hidden possibilities of influencing the reader.

The text as an object of interdisciplinary research is of particular interest, since researchers, considering the influencing ability of the text to manage personnel, must take 
into accountthe nature of a number of managerial, psychological and linguistic phenomena. The simple transfer of the conclusions obtained as a result of the analysis of stylistically marked elements within sentences or super-phrasal units to those phenomena that were observed throughout the entire text of the control document, in most cases proved untenable.

Modern text linguistics already has theoretical provisions that can create a solid basis for studying the influencing features of the text. In many countries, work is underway to define both the concept of "control text" and a number of concepts related to the problem of text. The beginning of the work of linguists in this field was laid by the colloquium in Constance (1968) [1]. During the colloquium, the main directions of the multifactorial study of the text were identified, although in a very general form.

Currently, there are two approaches to text theory: the first approach is an attempt to create a formalized grammar of the text, i.e. to define postulates and rules according to which it is possible to model text structures with the choice of the best possible impact. This approach is typical for West German and American scientists. The other is the study of specific patterns of the structure and functioning of texts, as well as the creation of text theory as a basis for studying the real linguistic material of a management document. The main attention is paid to the communicative aspect of the functioning of document texts in a single information system of databases and management communication of production. In the most general sense, a management text is characterized as an influencing and motivating speech unit consisting of a finite number of grammatical structures and containing a volume of special information that exceeds the sum of the information volumes of its constituent units. The unity of the text is one of its most important properties and can be traced both in terms of expression and in terms of content, where they are updated. This ability allows speech text techniques not only to function as marked elements (focus), but also to serve as a means of creating intra-text links that ensure the integration of the text and contribute to the disclosure of the content of the management text (Topic).

The term "actualization" is considered as drawing the recipient's attention to the content against the background of an unmarked environment. This understanding of extension allows us to describe this phenomenon on the basis of individual stylistic techniques and to reveal the essence of actualization as a linguistic phenomenon.

Actualization in the management text differs from actualization at lower levels in its consistency, which allows not only to draw the recipient's attention to individual elements of the text, but also to establish separate connections between these elements, which contributes to the creation of the integration of the text into the performer's consciousness.

Actualization in the management text differs from actualization at lower levels in its systemic nature, which allows not only to attract the attention of the recipient to individual elements in the text, but also to establish separate connections between these elements, which contributes to the creation of the integration of the text into the consciousness of the performer.

Representing a higher-order phenomenon, the actualization of a management text is not only a simple accumulation of one-step stylistic techniques in the text: there are qualitative differences between a single stylistic technique that is not related to other stylistic techniques in the text, and a stylistic technique that forms an indicator of connection. The change in the nature of a number of properties of stylistic techniques in the text is due to the change in their influencing power and functional orientation, which takes place during the transition of the technique from the category of focal techniques to a means of creating the integration of the text in management communication.

Turning into one of the links in the text of the chain called the multi-step technique above, each stylistic technique undergoes a number of changes. Among them, increasing predictability plays an important role. Limited, as a rule, by the framework of one or more 
super-phrasal units, the context represents regular predictability, while the reception implemented in this context is unpredictable for the decoding receiver. This creates an opposition between a marked stylistic device and an unmarked environment, between a stylistically unpredictable device and a predictable context. The effect of "deceived expectation" resulting from the decoding of this single reception becomes the basis for the extension of the reception. In the text, the process described is different. If at the level of text units a certain stylistic technique is aimed at typifying the selection of the particular, the specific, then in the text the same stylistic technique is aimed at creating a single, general whole.

This entails a fundamental change in the process of creating the opposition predictability/unpredictability, marking/unmarking. A stylistic device that is unpredictable within the text units becomes predictable in the text

It follows from this that those predictable stylistic devices that represented a weak member of the opposition within the text units are transformed into a strong member of the opposition in the text precisely due to their predictability. The high degree of predictability of the stylistic device that forms the link indicator undoubtedly reduces its effectiveness as a stylistic phenomenon at the level of text units, but at the same time significantly increases its effectiveness as a means of creating intra-text links across the entire text of the management document.

By increasing the predictability of single-stage techniques, the transition of these techniques from the phenomena of "focus" to the means of communication takes place. This transition does not, however, reduce the information content of the reception: only the nature of the information transmitted by the reception changes. Multi-step reception is not only one of the means of creating its integration in the text, but also participates in the process of transmitting the information that the text carries. Every literary text has a content that represents a certain amount of information, which, however, exceeds the sum of the volumes of information of those large segments that are units of the text. Multi-step reception not only connects these units, but also contributes to the transfer of an additional amount of information.

Such participation of a multi-stage technique in the disclosure of the contents of the text becomes possible due to the fact that this peculiar set of interrelated and interdependent stylistic techniques functions throughout the text and, therefore, contributes to the decoding of information at the highest level of analysis.

The process of decoding units of various levels is generally characterized by a gradual transition from units of lower levels to units of higher levels, and it is this transition that provides at each stage of decoding the increment of information that creates a qualitative difference between units of a lower level and units of a higher level. Each unit is characterized by semantic and structural completeness and is considered as an object of study a kind of closed system in cases where it is considered outside the boundaries of the higher-level unit of which it is an integral part[14-15]. However, being studied not in an isolated form, but as one of the components of a higher-level unit, the same unit turns into an open system, the meaning of which cannot be determined without taking into account the meaning of other units, both at the same level and at a higher level.

\section{Discussion}

In practice, the researcher observes a shift in the emphasis of the text in the framework of increasing the information component of management and the introduction of remote communication systems in production processes in the development of the digital economy.

Management decisions in the company's management system are functionally distributed across the areas of responsibility, while the participants in management 
communication are unequal among themselves and each has a designated limit of competence and responsibility. The performer in production communication functions as a full-fledged source of the text and forms an auxiliary text on the ground, conducting detailed communication with all structural divisions

The features of production communication are:

- significant formalization of the text,

- use of template phrases,

- stylistic heterogeneity, overloading with clerical writing,

- introduction of neologisms and calcifications, including in the presence of a stable term

All this does not contribute to clarity in understanding the text from a linguistic point of view and complicates operational management from an organizational point of view.

To improve the quality of the organization of labor in the enterprise and the efficiency of document management, it is considered appropriate to introduce the simulation of organizational activities in management communication at the stage of planning and organizing the project.

Simulation involves the experimental development of effective behavior of a project or one of its structures in conditions close to real ones. Information modeling allows you to build a realistic model of the behavior of the company's management communication..

\section{Conclusion}

Communication involves the involvement of all participants in the production process in a single information environment that is characterized by a common sign system of information transmission, cognitive abilities of information perception, the ability to exert mutual influence in the communication process. The manager exerts an orienting influence on the employee, which changes the environment in such a way as to cause a certain reaction on the part of the recipient of the information. The peculiarities of industrial communication with the use of modern information programs are the adaptation of traditional forms of oral and written speech to the possibilities of virtual space. In this regard, the phenomenon of oral written speech is highlighted. Oral written speech involves the maximum approximation of communication to oral interaction by means of writing. Its distinctive features are:

1. Conciseness laconism the desire to express as much information as possible in the smallest text segment;

2. Saturation of speech with emotional statements, attempts to convey the intonation and emotions that are traditionally present in oral speech. Virtual production communication in many ways imitates communication in reality;

3. Forced refusal of strict compliance with the rules of spelling and reduction of time for the preparation and publication of the answer. For communicants in the conditions of modern network management, the speed of reaction and relevance, the timeliness of the response to the request of the communication partner is extremely important;

4. At the same time, communication involves many communicants, each of whom is equally involved in communicating with each other;

5. The presence of the phenomenon of delayed communication. This phenomenon does not imply the coincidence of the terms of writing the answer, their reading by users who are located in different time zones or have different access opportunities to a stable production information and communication environment.

All these features determine the specifics of the manifestation of the effectiveness of enterprise management and can be modeled by means of modern information programs with the choice of the best influencing factor. At the same time, it should be understood that virtual production communication is always an addition to objective reality, when a person 
employed in the real world can spend a limited amount of time on a message on a relevant topic (the temporal factor) and at the same time should be among the first to indicate a position on this issue (the media priority factor).

\section{References}

1. N.J. Albury, Crit. Inq. Lang. Stud. 12(4), 256-282 (2015). doi:10.1080/15427587.2015.1096732

2. D.S. Anderson. Lang. Educ. $25 \quad$ (4), 273-289 (2011). doi:10.1080/09500782.2011.577218

3. M.De Meulder, A. Kusters, E. Moriarty, J.J. Murray, Multicult. Dev. 2 (2), 1-15 (2019). doi:10.1080/01434632.2019.1592181

4. P. Garrett, Cambridge Univ. Press, Cambridge, UK (2011). doi:10.1017/CBO9780511844713

5. King K.A., Hermes M. Lang. Ident. Educ. 13 (4) (2014), pp. 268-282, doi:10.1080/15348458.2014.939029

6. A. Kusters, Lang. Soc., 43 (2) 139-158 (2014). doi:10.1017/S0047404514000013

7. A. Kusters, M. Spotti, R. Swanwick, E. Tapio, Int. J. Multiling 14 (3) 219-232 (2017). doi:10.1080/14790718.2017.1321651

8. Safar J. Appl. Ling. Rev. (2017). doi: 10.1515/applirev-2017-0082

9. J. Safar, O. Le Guen, G. Collí Collí, Hau M. Collí, Sign Lang. Stud. 18 (4), 488-516 (2018). doi:10.1353/sls.2018.0014

10. Sallabank J. Multilingua 38 (2018). doi: 10.1515/multi-2018-0002

11. T.B. Mikheeva, E.V. Murugova, SHS Web of Conf (2019). doi.org/10.1051/shsconf $/ 20197007003$

12. S.V. Pervukhina, O.A. Evtouchenko, L.Iu. Kotliarenko, M.P. Churikov, SHS Web of Conferences. Curr. Iss. Mod. Ling. Hum. 232-244 (2020). doi: $10.1051 /$ shsconf $/ 20208801013$

13. M.A. Tamarkin, A.N. Isaev, E.V. Murugova, V.I. Butenko, MATEC Web of Conf. (2018). doi:10.1051/matecconf/201822601025

14. S. Pervukhina, V. Demchenko E3S Web of Conf. (ITSE 2020). 18033. doi:10.1051/e3sconf/202021018033

15. N.B. Boeva-Omelechko, M.R. Zheltukhina, O.P. Ryabko, G.G. Matveeva, E.V. Murugova, I.A. Zyubina, Space and Culture, India 4, 112-121 (2018). doi: 10.20896/saci.v6i4.387 